\title{
Online Tea Cafés: Using Caring Science to Transform Digital Learning Spaces and Advance Nursing Leadership
}

Lisa Sara Goldberg

Dalhousie University, lisa.goldberg@dal.ca

Les T. Johnson

Dalhousie University, lestjohnson@dal.ca

Sandra F. Murphy

Dalhousie University, sandra.f.murphy@dal.ca

Follow this and additional works at: https://qane-afi.casn.ca/journal

Part of the Educational Leadership Commons, Online and Distance Education Commons, and the Other Nursing Commons

\section{Recommended Citation}

Goldberg, Lisa Sara; Johnson, Les T.; and Murphy, Sandra F. (2020) "Online Tea Cafés: Using Caring Science to Transform Digital Learning Spaces and Advance Nursing Leadership," Quality Advancement in Nursing Education Avancées en formation infirmière: Vol. 6: Iss. 3, Article 6.

DOI: https://doi.org/10.17483/2368-6669.1223

This Article is brought to you for free and open access by Quality Advancement in Nursing Education - Avancées en formation infirmière. It has been accepted for inclusion in Quality Advancement in Nursing Education - Avancées en formation infirmière by an authorized editor of Quality Advancement in Nursing Education - Avancées en formation infirmière. 
Online Tea Cafés: Using Caring Science to Transform Digital Learning Spaces and Advance Nursing Leadership

\section{Cover Page Footnote}

The authors wish to acknowledge the often profound and always generous contributions of the students thusly making this manuscript possible. Les auteures aimeraient souligner les contributions souvent significatives et toujours généreuses des étudiantes, sans qui ce manuscrit n'aurait pu voir le jour. 
Despite nurse educators integrating active learning pedagogies, opportunities for interaction and reflection, and elements of social presence into digital learning environments, students indicate online courses continue to lack relevance to clinical practice and isolate them from their peers (Smith et al., 2009). With current trends moving in the direction of more distance, technology-enabled, and online learning (Donovan et al., 2019; Myrick \& Pepin, 2016), and the latest constraints to teaching and learning resulting from Covid-19, nurse educators continue to question their ability to prepare the next generation of nurses by way of such modalities. The purpose of this article is to describe how typical asynchronous online discussions, which are highly structured with minimum/maximum word counts, posting frequencies, and content requirements, can be transformed into active learning spaces where students are engaged by grounding their design in caring science.

Developing a distance-learning pedagogy that seeks to explore the power of compassion in the digital world (Sitzman \& Watson, 2017) as a core underpinning for a compulsory course in nursing leadership and professional formation is both timely and necessary. Compassion grounded in caring science can foster a more reflexive and politicized (Goldberg 2015, 2018) environment to grow one's leadership capacity. This process can assist nursing students to better understand how to leverage their knowledge in relation to structural competencies (Metzl \& Hansen, 2014) when advocating for historically underrepresented communities.

Using examples from the course, the authors demonstrate the ways in which the Tea Cafés (weekly, asynchronous online discussion activities), a pedagogical strategy grounded in caring science, fostered an engaged learning environment where students not only thrived and developed a real sense of community but also a deeper recognition of nursing leadership and the importance of reflexivity, compassion, and politicization in how to enact leadership practices, including those with historically underrepresented communities (Goldberg et al., 2017).

\section{Literature Review}

To understand the relevance of caring science as both a theoretical and pragmatic underpinning to online learning and its ability to re-imagine digital spaces, Goldberg et al. (2017) begin with a review of the literature in relation to asynchronous online discussions, which served as the pedagogical foundation of the Tea Cafés. A brief overview of caring science will be addressed to set the stage for the framework of the course. This, in turn, provides an understanding of how and why caring science offers transformative possibilities for the learning environment for students, thus fostering a deeper understanding of how to better care for-and with - historically underrepresented communities, not forgetting that we ourselves as nurses (and nursing students) are also members of historically underrepresented communities.

\section{Asynchronous Online Discussions}

Asynchronous discussions are a prominent feature of almost every online course. Although an online offering is typically designed to align with other features of the Learning Management System (LMS), including tools designed for communication (announcements, email), content delivery, and assessment (dropbox, grades, e-portfolio, etc.) (Major, 2015; McCabe \& GonzálezFlores, 2017), discussions are key elements in promoting interactivity between educators and students, as well as between learners and their peers.

The literature is replete with examples of design elements that promote successful asynchronous online discussions (Jain \& Jain, 2015; Milman, 2017; Woods \& Bliss, 2016). 
Structured discussions, such as those with clearly defined expectations (e.g., use of rubric, associated grades) or where students are assigned specific roles or placed into groups, tend to have greater levels of student engagement (Aloni \& Harrington, 2018; DiPasquale \& Hunter, 2018; Ellis, 2008). When educators make deliberate efforts to create a sense of community, attend to diverse learner backgrounds and interests, and participate in discussion activities, discussion post quality and perceived learning on the part of students improves (Aloni \& Harrington, 2018; Schindler \& Burkholder, 2014).

\section{Structured discussions}

Student engagement, discourse quality, and sense of community in asynchronous online discussions are influenced by a number of factors. When participation in asynchronous online discussions are associated with a grade, student engagement increases (Hew et al., 2010). In a case study of five graduate-level online courses, Vonderwell et al. (2007) found students responded positively to evaluation criteria for asynchronous discussion, indicating that specific, detailed rubrics allowed them to understand educator expectations and to self-assess their own discussion contributions before posting. However, although graded discussions led to more participation, students in one study (Osborne et al., 2018) indicated a disconnect between their desire to engage in deep, thoughtful conversations with peers and the need to contribute a post to fulfill the requirements of the marked assignment.

Studies have shown that learners who volunteer or are assigned to play specific roles in the discussion, for example as a facilitator, leader, or moderator, have higher levels of participation (Vonderwell et al., 2007; Xie et al., 2014). In these cases, students not only keep track of their classmates' contributions but are better able to assess their own learning and participation (Vonderwell et al., 2007). In an inquiry into the effect of being assigned the role of a facilitator on the individual's and group's discussion participation, Xie et al. (2014) found that student moderators posted more (yet shorter) messages to a greater diversity of classmates and stayed logged in longer than when not in a leadership role. The research indicated, too, that the presence of a student facilitator had no significant effect on group participation or performance.

At the same time, in a multiple case study, Hew (2015) found that $65 \%$ of student participants indicated they preferred instructor-facilitated asynchronous online discussions over those led by peer moderators. Participants cited that instructors would guide, motivate, and shape student discussion, sharing expertise and resolving conflicts when they arose. For the $35 \%$ of students who preferred peer facilitation, they indicated their preference stems from the fact that student-led discussions are a more comfortable, less stressful environment, with less worry about posting the "right" answer in response to a discussion prompt (Hew, 2015).

How the discussion activity is structured also has an effect on student participation. In a pilot study around the voluntary use of an online discussion board in conjunction with a Fundamentals of Nursing Concepts course, Hudson (2014) found that the teaching strategy employed on any given week affected discussion board participation. On weeks with facultygenerated discussion questions and interactive case studies, there was more participation (60-70\%) than in weeks where the discussion activity revolved around watching videos or reading articles $(<17 \%)$. Similarly, in a mixed methods study that used surveys and analysis of students' discussions posts to look at the development of critical thinking in an asynchronous online discussion, Novotny et al. (2016) found students rated instructor-facilitated discussions as having more impact on their critical thinking than those discussions that were led by a student facilitator. 
However, it was noted that the posts in student-facilitated discussions represented higher-level cognitive processes (i.e., synthesis) than those in discussions led by instructors.

Zydney et al. (2012) explored how structure in asynchronous online discussions affected the cognitive, social, and teaching presence (Anderson et al., 2001) of students. In their quasiexperimental study, one online graduate class was given a communication protocol to follow, while another was given an open-ended discussion question instead. Results indicate that the course that was assigned use of the protocol had a more balanced representation of cognitive, social, and teaching presences, where students made connections with other students' ideas, supported and complimented each other, and shared their experiences and knowledge with their peers. The non-protocol group discussions were comprised more of individual posts and showed less interaction (Zydney et al., 2012).

\section{Student-educator interactions}

Shackelford and Maxwell (2012) conducted a study to determine what types of studenteducator interactions contributed to a sense of community in graduate-level online courses. Results indicated that all forms of interactions, including professor modeling, support, and encouragement; discussion facilitation; multiple modes of communication; and required participation, added to the learners' sense of community. Educator modeling, although not a type of interaction that occurred frequently, was rated as highly important.

Cranney et al. (2011) analyzed ten archived courses to look for correlation between instructors' participation, both in terms of amount of time and quantity of discussion posts, and students' grades in the online discussions. Researchers found a positive relationship between the amount of time instructors spent participating in the course and the students' performance. However, there was no correlation between the number of faculty contributions to the discussion and the students' average overall discussion grade.

Studies have also shown that a conversational tone on the part of the instructor increases students' engagement, learning, and performance (Clark \& Mayer, 2011). In a mixed-methods study on the use of an asynchronous online discussion forum in a graduate health leadership course, Osborne et al. (2018) found instructors modeled interaction that was informal and supportive in an effort to foster student engagement and build community and connection amongst the learners.

\section{Caring Science}

Originating with world-renowned nursing theorist Jean Watson (2008), caring science offers the practitioner a transformative way of engaging in the world. Unlike other theories that are often considered too philosophical, having little to no applicability to the everyday practices of practitioners, caring science offers something different: a theory grounded in a practical approach to being-in-the-world. Although caring science remains a critical ontology, epistemology, and ethic, it also supports a pragmatic framework: one grounded in the 10 caritas processes and the importance of transpersonal caring (Watson, 2005, 2008). As such, caring science provides every practitioner, novice, or expert, a transformative approach to their practices-personally, professionally, and within systems (Watson, 2005, 2008). Thus, caring science fosters ways of re-visioning relationships between persons: educators and students, nurses and patients, managers and staff, by beginning with the place of the reflexive self (Goldberg, 2015, 2018). 


\section{Ten Caritas Processes and transpersonal caring}

Caring science asks both educators and learners alike to move beyond the "ego self" to embody practices that create trusting and healing environments (Goldberg, 2015; Watson, 2008). The 10 Caritas Processes (List 1) inspire the practitioner of caring science on a daily basis to create safer spaces, embrace diverse and multiple forms of knowledge(s), be present with both positive and negative feelings, and infuse hope in others while simultaneously being open to the mysteries of the universe (Watson, 2008). In addition to the 10 Caritas Processes (Watson, 2008), transpersonal caring is an inherent underpinning of caring science. This entails that when one is authentically present with another, they fully embrace the storied experiences and inner world of the other. "Transpersonal caring also seeks to go beyond the self and beyond the here and now, reaching to deeper connections with the spirit and with the broader universal consciousness" (Sitzman \& Watson, 2017, p. 17-18). Transpersonal caring reminds educators that individual relationships shared with students transcend the here and now, often with far-reaching effects. Thus, the language an educator uses can transcend far beyond an individual educator-student relationship. Being mindful of language is then essential to transpersonal caring (Goldberg, 2018).

Transpersonal caring and the 10 Caritas Processes (Watson, 2008) have been applied in numerous contexts and environments. These include, but are not limited to, educational settings (Hills \& Watson, 2011), emergency and paediatric health care contexts (Brenol, et al., 2019; Revels, et al., 2016), and in the advancement of equity, diversity, and inclusivity, particularly with equity seeking groups (Goldberg et al., 2017). More recently, however, innovation and compassion have been applied to the digital world with the development of cyber caring, showcasing the potential impact caring science offers for advancing online learning and teaching (Sitzman \& Watson, 2017).

\section{List 1}

The 10 Caritas Processes ${ }^{T M}$

1. Practicing loving-kindness and equanimity within the context of caring consciousness.

2. Being authentically present and enabling and sustaining the deep belief system and subjective life world of the self and the one-being cared for.

3. Cultivating one's own spiritual practices and transpersonal self, going beyond the ego self.

4. Developing and sustaining a helping-trusting, authentic caring relationship.

5. Being present to, and supportive of, the expression of positive and negative feelings.

6. Creatively using the self and all ways of knowing as part of the caring process, engaging in artistry of caring-healing practices.

7. Engaging in a genuine teaching-learning experience that attends to wholeness and meaning, attempting to stay within the other's frame of reference.

8. Creating a healing environment at all levels, whereby wholeness, beauty, comfort, dignity, and peace are potentiated.

9. Assisting with basic needs, with an intentional caring consciousness, "administering human care essentials," which potentiate alignment of mind-body-spirit, wholeness in all aspects of care.

10. Opening and attending to mysterious dimensions of one's life-death, soul care for the self and the one-being-cared-for, "allowing and being open to miracles." 
In what follows, the authors, including a course professor from nursing, an educational developer from the university's teaching and learning centre, and teaching assistant (TA) in nursing, build on the work developed by Sitzman and Watson (2017) by first describing the online course they delivered on nursing leadership and professional formation. Second, they discuss their innovative pedagogical strategy, which, grounded in caring science, fostered an engaging learning community where students developed leadership skills, including how to leverage their nursing knowledge via compassion, reflexivity, and politicization to advocate for historically underrepresented communities (Goldberg, et al., 2017). Third, student work samples are shared. Lastly, the authors provide the results from the course in the form of informal student feedback and formal university course evaluation measures.

\section{The Course}

In the winter of 2019, the first author was responsible for carrying out an online course on nursing leadership and professional formation with undergraduate students. Given the newly modified curricula established in the School of Nursing, the course was at a point in the rotation where students had minimal clinical experience. There were 63 students enrolled in the eight-week course. The first session of the class was held face-to-face to allow students to meet the course professor and TA, discuss the overall objectives of the course, review the syllabus, and do a small onsite assignment. The onsite experience also fostered an opportunity for the students to meet their counterparts: peers who would be in their online Tea Café group for the remainder of the course. After the first class, the remaining seven modules were delivered solely online.

Each week, the course focused on a different topic in nursing leadership and professional formation, including everyday ethics, caring science leadership, strength-based nursing leadership, conflict resolution, health care systems, organizations, and structures. The course learning outcomes were designed for students to be able to describe ethical, legal, and professional boundaries and accountability; use reflexive thinking in leadership and in the development of therapeutic relationships; apply nursing theories to their practice; analyze organizational management structures; facilitate problem-solving in various healthcare settings; and articulate the unique roles of nurses within intra and interprofessional teams. These learning outcomes were aligned with the three course assignments: a group case study, an individual leadership paper, and weekly discussion activities (Tea Cafés). The latter allowed students practice opportunities in their achievement of the learning outcomes and emphasized major course concepts of communication, relational practice, and collaboration, among others.

The content of the course included readings and guiding questions, as well as elements that took advantage of the digital learning environment, such as videos, images, and weblinks. As the course was infused with compassion via caring science, the authors also considered the importance of including materials that fostered a lens of equity, diversity, and inclusivity (EDI). In other words, starting from a place of compassion, the authors used a student-centric approach: loving kindness infused decision-making with flexibility, equanimity, and generosity (Caritas Process 1). This approach encouraged reflexive and politicized approaches to the weekly Tea Café contributions and assignments. Because nursing holds advocacy (politicized practice) as central to its mandate, fostering self-awareness in relation to one's own biases (reflexivity) is necessary to ground a practice commensurate with the Canadian Nurses Association Code of Ethics (2017) and the Nova Scotia College of Nursing Standards of Nursing Practice (2017). Addressing work on structural competencies; the invisibility of Black nurse leaders, persons with (dis)Abilities, and Indigenous communities; and the cultivation of inclusivity with 2 SLGBTQ+ people and other 
historically underrepresented communities, fostered critical leadership skills in diverse ways previously unfamiliar to many students.

\section{The Tea Cafés}

The weekly Tea Cafés were discussion, reflection, and sharing activities that took advantage of the spontaneous face-to-face dialogue while capitalizing on the flexibility of asynchronous, online interactions to foster pithy and generous dialogue. Rather than relying on the typical question-response paradigm typical of online course discussions, the Tea Cafés encouraged students to engage with the content and express their learning through creative modalities. In this section, the authors describe how the Tea Cafés came about, explain the pedagogical principles that drive their success, and share sample student contributions.

\section{Course Design Consultation}

Although the course professor (first author) and TA (third author) were the online presence for the course, the educational developer (second author) played a critical role in the course design. Typically, when a faculty member is preparing to teach online for the first time, as was the case with the first author, an educational developer will recommend the professor consider a straightforward course design and relatively simple learning technologies in an effort not to overwhelm the faculty member, while at the same time maximizing student learning. By substituting course components that prove successful in the face-to-face context with their online counterparts, educators can ease their entry into this unfamiliar online space.

However, in this course, the course professor (first author) was determined to do things differently to avoid the phenomenon of "death by discussion board" (Tennant et al., 2010, p. 136), where students review the course content, construct a lengthy response that adheres to a prescriptive format, and post it in an online discussion forum. As an educational developer (second author), the challenge was to honour the course professor's presence and personality, the pedagogical approach grounded in caring science (Goldberg, 2018), and the course content on nursing leadership, while assisting in the design of a course being taught by a first-time-online professor.

As an educational developer, the second author had previous practice where students expressed their understanding of the content and engaged with each other in ways beyond traditional academic text, including but not limited to, having students write poems, make bumper stickers, take photographs, and produce videos. Upon hearing this suggestion, the first author recalled attending a Caring Science and the Arts Conference in the fall of 2018 in the United Kingdom. It was here where attendees did a session on poetic inquiry (McCulliss, 2013) that involved writing haikus. Remembering the power of this experience, along with the joy created in the session, this kick-started a flurry of ideas on how the students would be able to use a variety of activities, including haiku poetry, to engage with the course content.

The end result of the consultative process was the Tea Cafés, a virtual space designed to further dialogue, understanding, and knowledge. The Tea Cafés were described in the syllabus as "a place to emulate the kind of dialogue that transpires in the classroom: organic, spontaneous, and pithy without references or citations." The activities situated within the Tea Cafés called on students' abilities to access diverse forms of nursing knowledge, such as aesthetic, empirical, spiritual, ethical, political, historical, intuitive, and beyond. Inspired by the course professor's love

of "all things tea" and the face-to-face tradition of wheeling in a tea trolley with a selection of teas 
and treats to share with students, the online activities were named Tea Cafés. By incorporating an element of tea into the virtual classroom, students re-imagined the online learning environment as inviting and generous: a space to engage, share, explore, and play, indeed a result of the teaching team's compassionate approach framed in caring science (Goldberg, 2018; Sitzman \& Watson, 2017).

\section{Pedagogy of the Tea Cafés}

The success of the Tea Cafés in bringing caring science to the online classroom was the result of two main pedagogical choices by the course professor and teaching assistant. First, they removed the structures typical of an online, asynchronous discussion in their design of the Tea Cafés. Second, throughout the semester, they regularly modelled for students their expectations around participation in the Tea Cafés by sharing example postings and by supplying interactive, conversational videos each week based on the course content.

\section{Unstructured discussions}

The Tea Cafés were situated in the Learning Management System (LMS) in the discussion tools, but because of the emphasis on caring science, the discussions happened in a way that was different from the typical asynchronous discussion of an online course. First, the directions given to students in the syllabus and course site were contrary to what students have come to expect. Rather than providing a structure to guide students in writing their discussion posts - including due dates, word counts, citation requirements, etc.- the directions were more invitational and unstructured; they were built on the philosophy of an actual tea café: relaxed, conversational, and a place for thoughtful interaction.

The directions for Tea Café postings in the LMS stated students were to "...allow the conversation to evolve as if you were in the classroom..." The course professor and TA leveraged familiarity with classroom dialogue to promote online interaction guided by loving kindness and a caring consciousness (Caritas Process 1). Students were expected to respond to guiding questions through creative writing (e.g., haiku poetry) and imagery (e.g., photographic representations). This fostered an understanding of aesthetic knowledge for nursing and the creative use of self (Caritas Process 6). Rather than calling them Discussions, changing the name to Tea Cafés allowed students to experience them as conversations one might have at a café (Sapir, 1964), rather than what they were used to doing in a typical online class. Reimagining the language of a discussion board to Tea Cafés had a magical effect: the monotony of repetition and rules dissipated, shifting student activities to engaged, innovative, and highly motivated learning. It was in this spirit of reimagining that the authors used the Tea Cafés to inspire weekly online student learning through compassionate engagement to excellent effect. Students contributed multiple, substantive, and thoughtful posts, sometimes including references and/or citations (even though this was explicitly noted as neither expected nor required). This process created an authentic teaching and learning environment for both students and educators alike (Caritas Process 7).

\section{Modelling}

Modelling was another pedagogical strategy the course professor and TA used to promote compassion, reflexivity, and politicization in their students. Modelling was accomplished through two main practices: course professor and TA participation in the Tea Cafés and weekly video postings. Both the course professor and TA set the tone of the Tea Cafés by contributing their own 
posts to the weekly forum. If students were asked to write a haiku, the course professor and/or the TA also posted a haiku of their own as an example; if students were asked to post a photograph that represented a principle of nursing leadership, again, either the course professor or TA would post a photo too. These posts served to model expectations and to set the tone, which led to highquality posts from students (Osborne et al., 2018; Shackelford \& Maxwell, 2012). This approach further demonstrated an authentic teaching and learning presence by the course professor and TA, and a genuine commitment to creating a transparent and trusting space for learning (Caritas Processes 2,4,7).

Weekly videos featuring the course professor and TA also served to model expectations for students. Lasting anywhere from 10-15 minutes, the two would begin with a bulletin board of announcements and then have an informal dialogue about the weekly content, including examples from both the course professor's long clinical experience as a more senior nurse and the TA's experience, having recently graduated from the $\mathrm{BScN}$ program, as a more novice nurse. The videos gave them opportunities to preview the coming week's learning outcomes, content, and activities, while also allowing them to review and synthesize the previous week's materials and student contributions. The videos also served the purpose of transmitting information via a bulletin board (due dates, reminders, etc.), answering student questions, and providing general feedback. In an online course, videos are an effective way to create educator presence (Anderson et al., 2001) and build a sense of community. Most of all, the conversations between the course professor and TA in the videos continued to model The Caritas Processes (Watson, 2008) and mirrored the type of dialogue expected of students in the Tea Café. In other words, the dialogue between the course professor and TA was generous, inviting, and open (Caritas Processes 4, 7, 8). It created a sense of trust, authenticity and, ultimately joy because both were committed and passionate about what they were doing. These two practices, modelling and the weekly videos, led to Tea Cafés being a welcomed vehicle for students to express their understanding of nursing leadership and to engage in deep conversations with their classmates: personally, professionally and across issues of systems (Watson, 2008).

\section{Student Contributions}

Throughout the course, many responses were posted to the Tea Cafés using images to bring aesthetic representation of the week's content into view. These examples of student work illustrate person-centred care and reflexive practice, while also focusing a lens on equity, diversity, and inclusion: 


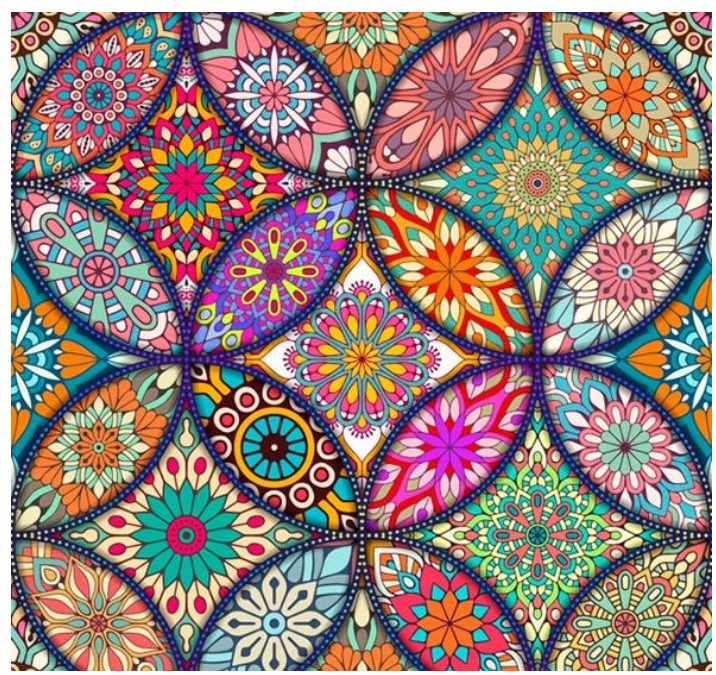

"This colourful mandala, composed of diverse shapes of all colours and sizes that overlap and intersect to create a cohesive, beautiful, complicated, whole, represents the different people we come into contact with as nurses."

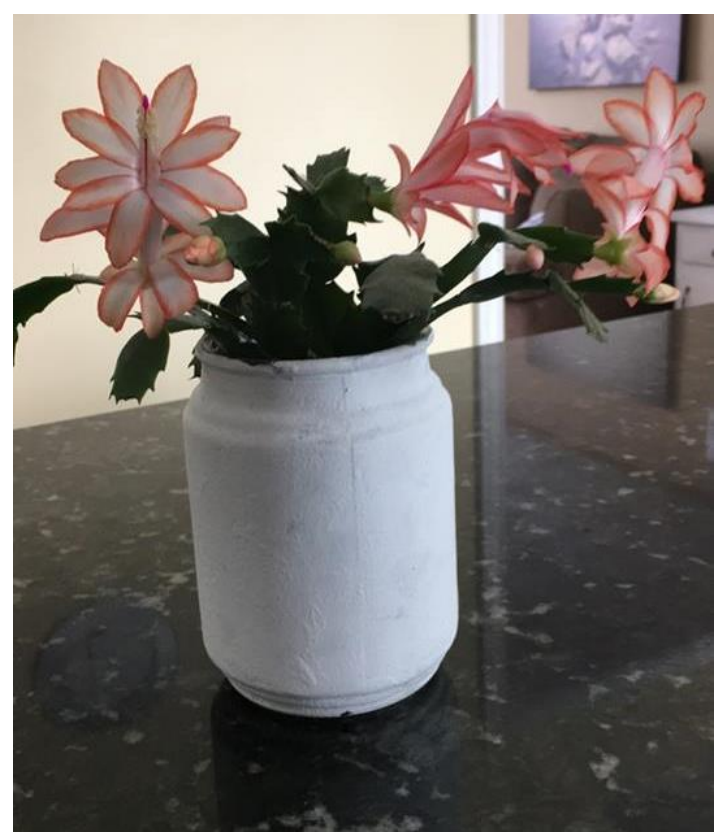

"My Christmas cactus is a good metaphor for person-centred care: As nurses we can't predict the most favourable conditions for our clients (just as I couldn't predict the conditions that made my cactus bloom), you need patience and creativity (it took a long time before I figured out the trick to get it to bloom), and to provide patient-specific solutions (I wouldn't put any of my tropical plants on the window sill because they'd die from the draft)."

In another Tea Café, students were also asked to write haiku poetry to express their thoughts on the week's readings with respect to equity, diversity, and inclusion. These are example haikus from four students:

I am still a seed, but when I am planted I will grow up strong.

Lives are different.
Those who have added to the nursing profession left invisible

White, straight, middle class: 
We cannot assume to know what we have not lived.
Please put me in the background.

Let me learn from you.

\section{Student Feedback}

Students were given two specific opportunities for providing feedback on the course: a midterm course evaluation adapted from Stephen Brookfield's (2017) Critical Incident Questionnaire (CIQ) and at the end of the semester through the university's course evaluation process.

\section{Midterm Evaluation}

As part of the midterm course evaluation, students responded to five questions. When students were asked, "What was the moment in the semester when you were most engaged or interested in what was happening?" most responses indicated participation in the Tea Cafés as the moment of highest interest and engagement. Students also noted the videos with conversations between the course professor and TA as well as the ability to post a photo to represent understanding as engaging moments. In response to the fifth CIQ question, "What has surprised you most about this course so far?" one student said that the Tea Cafés represented a "creative way to learn," allowing them to be open to "new information and ways of thinking." One student expanded on these ideas by writing:

I feel that this course has taught me so much, not just as a leader, but skills that I can take forward to any area of my nursing practice... This course on leadership could have been very formal and rigid, and I am so happy it was taken on a more holistic and caring level... This Tea Café also allowed all of us to have wonderful conversations and was certainly not 'death by discussion board.' :)

Through the midterm course evaluation survey, students also highlighted their professor's "affirmative and supportive presence" and surprise at "how engaging the professors are even though it is an online course."

\section{University and End-of-Semester Course Evaluations}

In all sections of the university's formal course evaluation process, the majority of students strongly agreed that the first author was organized, communicated clearly, showed enthusiasm, and provided constructive feedback, among other factors. On a five-point scale, the mean rating of overall teaching effectiveness was $M=4.36(n=17)$, which is higher than that of the department $(M=4.00)$, school $(M=4.10)$, or university as a whole $(M=4.14)$.

In the narrative section of the course evaluation, students commented on the Tea Cafés:

Among the day to day stress in this program, I looked forward to receiving [the professor's] feedback each week on my Tea Cafe postings because she had a strengthsbased positive approach to it. Although I found the content challenging at times, completing my work in this class each week quickly became one of the most rewarding and enjoyable times of my week. I simply cannot say enough good things about [this] professor. She truly made me understand and appreciate the value of leadership in nursing where I could never see this before. Thank you so much! [Student Ratings of Instruction Results, Winter 2020] 
Statistics from the LMS indicated that all of the students watched the weekly videos, with some students viewing them more than once. Student feedback also indicated that they found the weekly videos informative, interesting, and enjoyable to watch. As one student commented:

"[The] professor was always enthusiastic about what she was teaching which made her videos engaging and her topics much easier to learn. She gave us examples of how our outcomes are applicable to our careers as nurses which allowed us to see the bigger picture of leadership." [Student Ratings of Instruction Results, Winter 2020]

Evaluations also revealed students' satisfaction with the course content and informative, timely feedback on assignments. LMS usage statistics indicate that not only did every student post in the Tea Café forums, but all replied to at least one peer, with some students replying to up to five peers' posts.

\section{Conclusion}

With the current trend of nursing education moving in the direction of distance and online learning, developing an active learning pedagogy grounded in compassion is not only timely but relevant to advance nursing leadership skills for students learning in cyber spaces. Using a framework grounded in caring science, the authors were inspired to introduce the idea of the online Tea Café, an unstructured discussion activity, supported by weekly modelling and conversational videos. The purpose of this paper is, however, not a comparative one with Sitzman and Watson (2017), particularly as the work done through their course from which their text is written features 100 s of students, is free, and solely based on caring science.

This, on the other hand, is a required course that used caring science as a framework strategically woven throughout to foster unique opportunities for learning nursing leadership and professional formation. In so doing, students began to understand how and why it was critical to leverage their newly required knowledge in leadership (individually and collectively) to also advocate for historically underrepresented communities. 


\section{References}

Aloni, M., \& Harrington, C. (2018). Research based practices for improving the effectiveness of asynchronous online discussion boards. Scholarship of Teaching and Learning in Psychology, 4(4), 271-289. http://dx.doi.org/10.1037/stl0000121

Anderson, T., Rourke, L., Garrison, D. R., \& Archer, W. (2001). Assessing teaching presence in a computer conferencing context. Journal of Asynchronous Learning Networks, 5(2), 117.

Brenol, S., Goldberg, L., \& Watson, J. (2019). Caring for children who are technologydependent and their families: The application of Watson's caring science to guild nursing practice. Advances in Nursing Science, 42(2), 13-23. https://doi.org/10.1097/ANS.0000000000000238

Brookfield, S. D. (2017). Becoming a critically reflective teacher (2nd ed.). Jossey-Bass.

Canadian Nurses Association. (2017). Code of ethics for registered nurses. Retrieved from https://www.cna-aiic.ca/en/nursing-practice/nursing-ethics

Clark, R. C., \& Mayer, R. E. (2011). E-learning and the science of instruction: Proven guidelines for consumers and designers of multimedia learning ( $3^{\text {rd }} \mathrm{ed}$.). Pfeiffer.

Cranney, M., Wallace, L., Alexander, J. L., \& Alfano, L. (2011). Instructor's discussion forum effort: Is it worth it? MERLOT Journal of Online Learning and Teaching, 7(3), 337-348. https://jolt.merlot.org/vol7no3/cranney_0911.pdf

DiPasquale, J., \& Hunter, W. (2018). Critical thinking in asynchronous online discussions: A systematic review. Canadian Journal of Learning and Technology, 44(2).

https://doi.org/10.21432/cjlt27782

Donovan, T., Bates, T., Seaman, J., Mayer, D., Martel, E., Paul, R., Desbiens, B., Forssman, V., \& Poulin, R. (2019). Tracking online and distance education in Canadian universities and colleges: 2018. Canadian Digital Learning Research Association. https://onlinelearningsurveycanada.ca/publications-2018/

Ellis, H. A. H. (2008). Discussion structure: Does it influence student participation and learning in online discussions? (Unpublished doctoral dissertation). University of South Alabama, United States.

Goldberg, L. (2015). Cultivating inclusivity with Caring Science in the area of LGBTQ education: The self-reflexive educator. Focus on University Teaching and Learning, 23(3), 15-17.

https://cdn.dal.ca/content/dam/dalhousie/pdf/dept/clt/Focus/Vol23No3.pdf

Goldberg, L. (2018). Living a caritas consciousness: A philosophy for our everyday practices as nurse educators. In S. Horton-Deutsch \& J. Anderson (Eds.), Caritas coaching: A journey toward transpersonal caring for informed moral action in healthcare (pp. 41-53). Sigma Theta Tau.

Goldberg, L., Rosenburg, N., \& Watson, J. (2017). Rendering LGBTQ+ visible in nursing: Embodying the philosophy of caring science in nursing. Journal of Holistic Nursing, 36(3), 262-271. https://doi.org/10.1177/0898010117715141 
Hew, K. F. (2015). Student perceptions of peer versus instructor facilitation of asynchronous online discussions: Further findings from three cases. Instructional Science, 43(1), 19-38. https://doi.org/10.1007/s11251-014-9329-2

Hew, K. F., Cheung, W. S., \& Ng, C. S. L. (2010). Student contribution in asynchronous online discussion: A review of the research and empirical exploration. Instructional Science, 38(6), 571-606. https://doi.org/10.1007/s11251-008-9087-0

Hills, M., \& Watson, J. (2011). Creating a caring science curriculum: An emancipatory pedagogy for nursing. Springer Publishing Company.

Hudson, K. A. (2014). Teaching nursing concepts through an online discussion board. Journal of Nursing Education, 53(9), 531-536. https://doi.org/10.3928/01484834-2014082001

Jain, S., \& Jain, P. (2015). Designing interactive online nursing courses. Education, 136(2), 179188.

Major, C. H. (2015). Teaching online: A guide to theory, research, and practice. John Hopkins University Press.

McCabe, M. F., \& González-Flores, P. (2017). Essentials of online teaching: A standards-based guide. Routledge.

McCulliss, D. (2013) Poetic inquiry and multidisciplinary qualitative research. Journal of Poetry Therapy, 26(2), 83-114. http://doi.org/10.1080/08893675.2013.794536

Metzl, J. M., \& Hansen, H. (2014). Structural competency: Theorizing a new medical engagement with stigma and inequality. Social Science \& Medicine, 103, 126-133. http://doi.org/10.1016/j.socscimed.2013.06.032

Milman, N. (2017). Designing asynchronous online discussions for quality interaction in asynchronous online courses. Distance Learning, 14(3), 61-63.

Myrick, F., \& Pepin, J. I. (2016). Nursing education in the digital age / La formation en sciences infirmières à l'ère du numérique. Quality Advancement in Nursing Education - Avancées en formation infirmière, 2(1), Article 1. https://doi.org/10.17483/2368-6669.1080

Nova Scotia College of Nursing (2017). Standards of practice for registered nurses. https://cdn1.nscn.ca/sites/default/files/documents/resources/RN\%20Standards\% 20of\%20Practice.pdf

Novotny, N. L., Stapleton, S. J., \& Hardy, E. C. (2016). Enhancing critical thinking in graduate nursing online asynchronous discussions. The Journal of Nursing Education, 55(9), 514521. http://doi.org/10.3928/01484834-20160816-05

Osborne, D. M., Byrne, J. H., Massey, D. L., \& Johnston, A. N. B. (2018). Use of online asynchronous discussion boards to engage students, enhance critical thinking, and foster staff-student/student-student collaboration: A mixed method study. Nurse Education Today, 70, 40-46. https://doi.org/10.1016/j.nedt.2018.08.014 
Revels, A., Goldberg, L., \& Watson, J. (2016). Caring science: A theoretical framework for palliative care in the emergency department. International Journal of Human Caring, 20(4), 206-212. https://doi.org/10.20467/1091-5710.20.4.206

Sapir, E. (1964). Culture, language and personality: Selected essays. D. G. Mandelbaum (Ed.). University of California Press.

Schindler, L., \& Burkholder, G. J. (2014). Instructional design and facilitation approaches that promote critical thinking in asynchronous online discussions: A review of the literature. Higher Learning Research Communications, 4(4), 11-29. http://dx.doi.org/10.18870/hlrc.v4i4.222

Shackelford, J. L., \& Maxwell, M. (2012). Contribution of learner-instructor interaction to sense of community in graduate online education. MERLOT Journal of Online Learning and Teaching, 8(4), 248-260. https://jolt.merlot.org/vol8no4/shackelford_1212.pdf

Sitzman, K., \& Watson, J. (2017). Watson's caring in the digital world: A guide for caring when interacting, teaching, and learning in cyberspace. Springer Publishing Company.

Smith, G. G., Passmore, D., \& Faught, T. (2009). The challenges of online nursing education. The Internet and Higher Education, 12(2), 98-103. https://doi.org/10.1016/j.iheduc.2009.06.007

Tennant, M., McMullen, C., \& Kaczynski, D. (2010). Teaching, learning and research in higher education: A critical approach. Routledge.

Vonderwell, S., Liang, X., \& Alderman, K. (2007). Asynchronous discussions and assessment in online learning. Journal of Research on Technology in Education, 3(3), 309-328. https://doi.org/10.1080/15391523.2007.10782485

Watson, J. (2005). Caring science as sacred science. F.A. Davis Company.

Watson, J. (2008). Nursing: The philosophy and science of caring (rev. ed.). University Press of Colorado.

Woods, K., \& Bliss, K. (2016). Facilitating successful online discussions. Journal of Effective Teaching, 16(2), 76-92.

Xie, K., Yu, C., \& Bradshaw, A. C. (2014). Impacts of role assignment and participation in asynchronous discussions in college-level online classes. The Internet and Higher Education, 20, 10-19. http://dx.doi.org/10.1016/j.iheduc.2013.09.003

Zydney, J. M., deNoyelles, A., \& Seo, K. K. (2012). Creating a community of inquiry in online environments: An exploratory study on the effect of a protocol on interactions within asynchronous discussions. Computers \& Education, 58(1), 77-87.

http://dx.doi.org/10.1016/j.compedu.2011.07.009 